\title{
Recurrent Hypomagnesaemia, tackling modifiable risk factors
}

Moayed Alhelfi ${ }^{1}$, Yared N Demssie ${ }^{2}$

${ }^{1}$ Specialty Trainee-4, Diabetes and Endocrinology , ${ }^{2}$ Consultant Physician and Endocrinologist, ,Department of Diabetes and Endocrinology, Royal Blackburn Hospital

\section{Introduction}

Hypomagnesaemia is a common yet under-diagnosed electrolyte disorder. It has a high prevalence among patients admitted to acute and intensive care facilities. Mild hypomagnesaemia is mostly asymptomatic but more severe forms of magnesium deficiency could present with potentially serious neuromuscular, neurologic and cardiac manifestations.

Hypocalcaemia ( due to impaired PTH secretion and target tissue resistance) and hypokalaemia ( due to renal potassium wasting) commonly accompany hypomagnesaemia and partly account for its clinical manifestations.

Gastrointestinal loss and renal magnesium wasting are the two most common causes of hypomagnesaemia. Medications such as diuretics and proton pump inhibitors are well known causes of hypomagnesaemia. Treatment of hypomagnesaemia should address the underlying cause as well as replacing the magnesium deficiency to prevent recurrence.

\section{Case Scenario}

A 68 years old lady presented to the medical assessment unit with history of muscle cramps involving both hands and legs of five days duration. She also gave a history of diarrhoea of two weeks duration. Her background medical history includes hypertension, hypercholesterolemia and dyspepsia for which she was taking Irbesartan/Hydrochlorothiazide

combination tablets, simvastatin and omeprazole.

General physical examination revealed positive chovstek's and trausseau's signs. Her investigation results confirmed low adjusted serum calcium level of $1.22 \mathrm{mmol} / \mathrm{L}$ (Normal range 2.15-2.6 $\mathrm{mmol} / \mathrm{L}$ ) along with low serum magnesium level of $0.14 \mathrm{mmol} / \mathrm{L}$. Her serum 25 hydroxy-vitamin D level was also on the lower side at $14 \mathrm{ng} / \mathrm{ml}$ and PTH level was marginally raised at 8.3pmol/L. ECG showed normal sinus rhythm with borderline QT duration at 450milliseconds.

\section{Treatment}

She was treated with $10 \mathrm{mls}$ $10 \%$ calcium gluconate in $100 \mathrm{mls}$ $5 \%$ dextrose infusion over 5 minutes followed by $100 \mathrm{mls} 10 \%$ calcium gluconate in $900 \mathrm{mls} 5 \%$ dextrose infusion over 24hours. She also received $16 \mathrm{mmol}$ of magnesium sulphate infusion in 1 litre $5 \%$ dextrose over 24 hours. Her symptoms resolved with this treatment and both her serum calcium and magnesium levels returned to normal at $2.28 \mathrm{mmol} / \mathrm{L}$ and $0.75 \mathrm{~mol} / \mathrm{L}$ respectively.

However, she continued to have diarrhoea with an average frequency of 3 to 4 times per day. Her stool culture result was reported negative for bacterial pathogens but further investigation with flexible sigmoidoscopy confirmed the diagnosis of colitis for which she was started on a course of oral steroid therapy.

\section{Progress}

Despite on-going diarrhoea, the patient was discharged from hospital without any oral calcium or magnesium supplement. She also continued to take both irbesartan/hydrochlorothiazide and omeprazole tablets which further increased her risk for recurrent hypomagnesaemia. Not surprisingly the patient was readmitted two weeks later with recurrence of neuromuscular symptoms along with profoundly low serum calcium and magnesium levels of 1.4 and $0.15 \mathrm{mmol} / \mathrm{L}$ respectively.

She was once again treated with both calcium and magnesium infusion until her serum levels returned to normal. She was also maintained on oral magnesium glycerol phosphate at a dose of $24 \mathrm{mmol} /$ day in three divided doses. Her hydrochlorothiazide tablet was stopped to reduce renal magnesium wasting and her omeprazole tablet was replaced with ranitidine. She has remained asymptomatic since and both her serum calcium and magnesium levels have stayed normal( Figures 1 and 2).

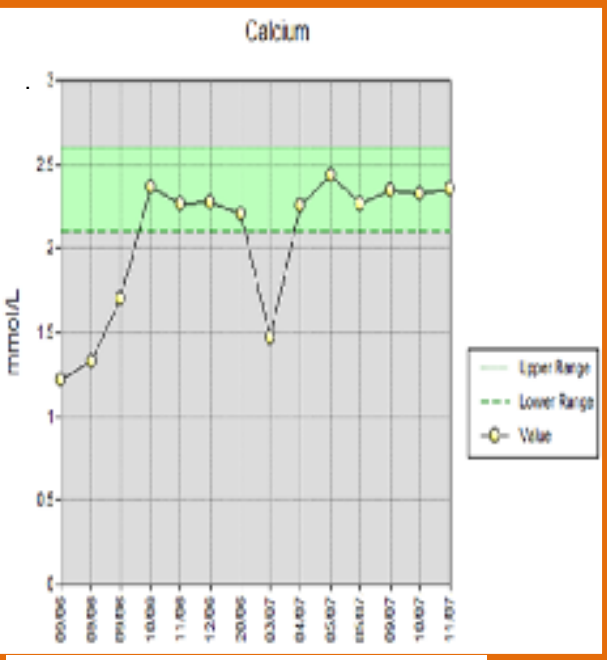

Figure1. Serial serum calcium level

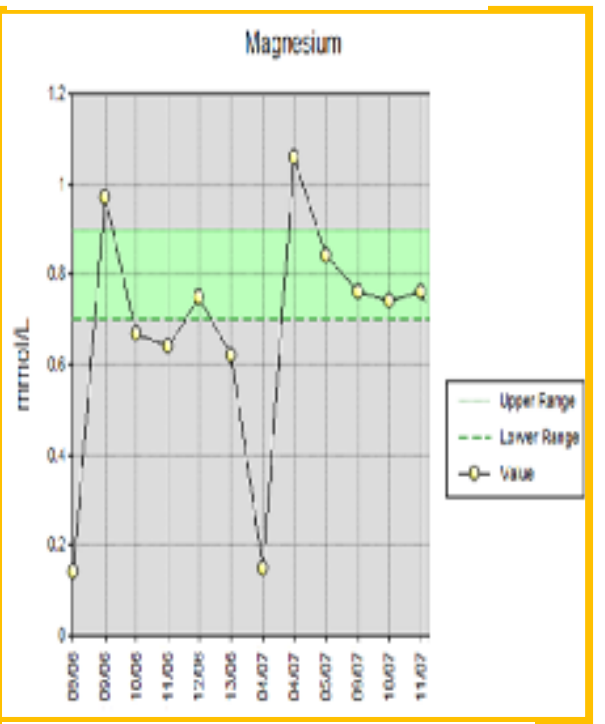

Figure2. Serial serum magnesium level

\section{Conclusion}

This case highlights the importance of identifying and correcting modifiable risk factors for recurrent hypomagnesaemia such as drugs as well as the need for prescribing maintenance oral magnesium supplementation in patients with ongoing magnesium

\section{References}

- Alan S L Yu et al. (2013). Evaluation and treatment of hypomagnesemia Available: www.uptodate.com. Last accessed 21/01/2014.

- al-Ghamdi SM, Cameron EC, Sutton RA. Magnesium deficiency. pathophysiologic and clinical overview. Am J Kidney Dis 1994; 24:737.

Hébert P, Mehta N, Wang J, et al. Functional magnesium deficiency in critically ill patients identified using a magnesium-loading test. Crit Care Med 1997; 25:749.

- Weisinger JR, Bellorin-Font E. Magnesium and phosphorus. Lancet 1998; $352: 391$

•Agus ZS. Hypomagnesemia. J Am Soc Nephrol 1999; 10:1616. 